\title{
DE ACADEMIAS, TRANSTERRADOS Y PARNASOS ANTÁRTICOS
}

\author{
TRINIDAD BARRERA \\ (Universidad de Sevilla)
}

Con el avance del siglo XVI la conquista va cediendo paso a la colonización a medida que se asientan los territorios. Los dos grandes virreinatos, Nueva España y Perú, se convierten en lugar apetecido para probar fortuna. La sociedad letrada va cobrando fuerza y pujanza al tiempo que van llegando a aquellas tierras algunos ilustres escritores y humanistas peninsulares, unos de primera fila pero también otros que no han conseguido hacerse con un puesto destacado en el Parnaso español y que intentan probar fortuna en América. Se cuenta que Miguel de Cervantes proyectó marcharse a América antes de escribir el Quijote y que finalmente no obtuvo los permisos necesarios y descartó la idea.

En la España de la primera mitad del siglo XVI predominaban aún rasgos arcaizantes $\mathrm{y}$ medievales que van disminuyendo poco a poco a medida que avanza el primer Renacimiento. El proceso es un poco más lento en América pero no por ello menos visible en la segunda mitad del siglo. El panorama cultural e intelectual se complica un tanto. Si, por un lado, Erasmo encarnaba la aspiración a un saber sin las trabas de una autoridad indiscutible y defendía un saludable relativismo, por otro la Iglesia acrecentaba continuamente su poder político y espiritual (precisamente por sus éxitos en América) y trataba de imponerlo sobre toda manifestación estética. La sociedad colonial se iba haciendo progresivamente más refinada, próspera e interesada en ejercer el mecenazgo de las artes: el prestigio personal asociado al ejercicio literario era una tentación creciente.

La poesía italianizante, la épica guerrera o cortesana, y la prosa doctrinal y erudita van encontrando más cultores y más público. Aunque persiste la crónica, lo más significativo es el surgimiento de la épica y la lírica culta, con las que se asienta la tradición literaria occidental que dominaría en los siglos venideros.

Mientras el interés por el recuento de la gesta conquistadora seguía manteniéndose alto, era evidente también que otros afanes empezaban a florecer entre las jóvenes letras coloniales. La vida se iba pacificando y organizándose, creándose una sociedad que quería ser reflejo de la metrópoli al tiempo que era distinta por razones de clima físico y espiritual. Las capitales virreinales fueron grandes focos de irradiación cultural donde cualquier acontecimiento, religioso o político, daba lugar a festividades y manifestaciones literarias, ya fueran representaciones teatrales o certámenes poéticos que celebraban desde una festividad religiosa como el Corpus hasta el nacimiento del hijo de un virrey, por poner dos ejemplos distintos. La palabra cumplía una visible función pública: la de reafirmar el poder colonial y los valores en los que se apoyaba. Surgen así, como he dicho, la prosa cortesana, la lírica culta, la épica, pero también la vertiente satírica y festiva de los que asumían la perspectiva burlona o escéptica del pueblo o de los descontentos que contemplaban con escepticismo y desdén toda esa retórica oficial.

En esta línea merece destacarse a un humanista, Francisco Cervantes de Salazar, que, nacido en Toledo, fue Catedrático de Retórica (Gramática Latina) en la Universidad de Osuna, antes de su partida a América. Había estudiado Humanidades y Derecho canónico

\section{Trinidad Barrera:}

Catedrática de literatura hispanoamericana de la Universidad de Sevilla. Su actividad crítica se ha centrado en la narrativa y en la poesía contemporánea. Ha sido profesora visitante en universidades europeas, latinoamericanas y norteamericanas. Sobre narrativa es la autora de La estructura de Abaddón el exterminador (1982), De fantasías y galanteos (Estudios sobre Adolfo Bioy Casares) (1981) y de ediciones de José Eustasio Rivera y Bioy Casares; en poesía ha trabajado autores como Oliverio Girondo o Baldomero Fernández Moreno y con especial atención los movimientos de vanguardia hispanoamericanos. En literatura colonial ha editado los Naufragios de Cabeza de Vaca (1985), la Primera parte del Parnaso Antártico, de Diego Mexía (1990), y la Brevísima relación de la destrucción de Indias, de Bartolomé de las Casas (2005), y estudiado, entre otros, Colón, fray Gaspar de Carvajal y Bernardo de Balbuena. Es autora también de la Letteratura hispano-americana, Del Centro a los Márgenes. Narrativa hispanoamericana del siglo $X X$ (2003), Las vanguardias hispanoamericanas (2006) y Asedios a la literatura colonial (2008).

De Academias, transterrados y parnasos antárticos

TRINIDAD BARRERA LÓPEZ 


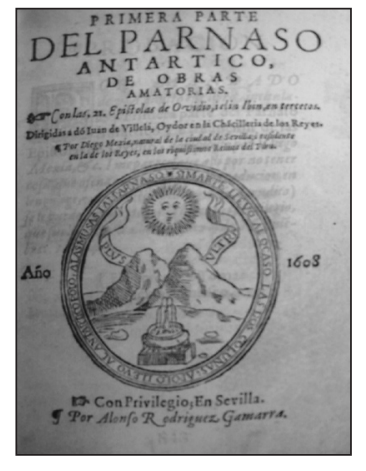

1

Juan Gil, «Diego Mexía de Fernangil, un perulero humanista en los confines del mundo», en Jesús María Nieto Ibáñez y Raúl Manchón Gómez, Humanismo español entre el Viejo Mundo y el Nuevo, León, Universidad de León, 2008, pp. 67-141.

2

Irving Leonard, Los libros del conquistador, México, FCE, 1979, p. 199.

De Academias, transterrados y parnasos antárticos

TRINIDAD BARRERA LÓPEZ en Salamanca, en España. Admiraba la prosa del erudito pensador del renacimiento, amigo de Erasmo, Juan Luis Vives y había comentado sus conceptos sobre la educación. En 1546 dedicó a Hernán Cortés un diálogo sobre la dignidad del hombre y fue el mismo Cortés el que le animó a ir a México, donde llegó a ser de nuevo Catedrático de Retórica en la Universidad mexicana. Con objeto de dar a sus estudiantes un texto de buena construcción latina, Cervantes de Salazar siguió los pasos de su maestro Vives y utilizó el «diálogo» para describir la capital mexicana en 1554. Con el nombre de Diálogos latinos, nos ha legado tres piezas maestras para el conocimiento de la capital virreinal a mediados del siglo XVI. En sus obras mexicanas parte, como humanista, de una tendencia inicial a observar y termina reflejando actitudes de contrarreforma y un punto de vista totalmente imperial.

Los poetas crecían por todos lados, el mexicano González de Eslava decía que en el México de su tiempo había más poetas que estiércol. Ocurre que en este siglo se implanta en América una institución que favorece el desarrollo de la lírica, la academia poética, siendo famosa la Academia Antártica de Lima. Con las academias se establecían escuelas y se orientaban los gustos, fueron sobre todo un esfuerzo de las sociedades ilustradas criollas pero contaron con el apoyo entusiasta de los ingenios peninsulares que celebraban a sus colegas americanos.

Aunque su origen remoto se encuentra en la escuela de filosofía griega, su significado viene dado por el Renacimiento, adquiriendo el sentido de una asociación de literatos formada para el cultivo y adelantamiento de las ciencias. Las academias modernas tienen su origen en Italia, en el siglo XVI, a imitación de ellas empiezan a fundarse en España centros similares. Llegaron a ser tan populares que apenas hubo palacio o casa de nobles donde no se reuniesen amigos atraídos por las musas. Dichas instituciones tenían sus cargos y estaban formadas por poetas, aristócratas y gente de relevancia social. La Antártica Academia de Lima estaba integrada principalmente por personas de origen andaluz: Cabello de Valboa y Diego de Aguilar, malagueños; Diego de Ojeda, Diego Dávalos y Figueroa y Diego Mexía, sevillanos; entre otros. No se olvide que Sevilla, punto de partida para América, contaba con tertulias literarias renombradas, la de D. Fernando Colón, la de Hernán Cor- tés, la escuela de gramática de Mal Lara, la casa de los duques de Alcalá, la de Arguijo, etc. La peruana bien pudo inspirarse en estos modelos. Se sabe que ya funcionaba en 1596 y continuaba en activo en 1608. Coincide en el tiempo con la tertulia mantenida en Tunja por otro sevillano, Juan de Castellanos, natural de Alanís. La institución académica siguió perviviendo en América hasta bien entrado el siglo XVIII, siendo famosas las academias palaciegas peruanas de D. Juan de Mendoza y Luna, marqués de Montesclaros, la del príncipe de Esquilache y la del marqués de Castell dos Rius, a principios del siglo XVIII.

En Perú merece destacarse la labor de dos poetas seguidores de Petrarca, el sevillano Diego Mexía de Fernangil y el ecijano Diego Dávalos y Figueroa, ambos son miembros de la Academia Antártica. Éstos, como otros, son homenajeados por sus colegas peninsulares y aparecen en las obras de Cervantes, Lope de Vega y Tirso de Molina. El «Canto de Calíope» en La Galatea (1584) o el Viaje del Parnaso (1614) de Cervantes así como el «Laurel de Apolo» (1630) de Lope, contienen el aliento de los peninsulares a sus colegas de allende el mar. Diego Mexía de Fernangil comparte con Dávalos su formación humanista, el petrarquismo italiano fue práctica habitual en ambos.

Nació Mexía en Sevilla, en fecha incierta, a mediados del XVI. De los datos que se conocen de su vida, hoy puestos al día por el estudio de Gil ${ }^{1}$ podemos afirmar que pertenecía a una familia de comerciantes de libros. Según relata Irving A. Leonard, el 22 de diciembre de 1576 un comerciante mexicano compareció ante notario para formalizar un pedido de libros «a uno de los principales vendedores de Sevilla, Diego de Mexía»². En opinión de Gil se trata del padre, también librero, así como el privilegio de la obra a la que nos vamos a referir la tiene un tal «Fernando Mexía», su hermano, también mercader de libros, vecino de Sevilla, según consta en la Suma del privilegio.

Lo cierto es que el nombre de Diego Mexía ha pasado a la historia literaria como el del autor de dos partes del Parnaso Antártico y no menos cierto es que la popularidad del curioso libro se debe a que alberga el famoso «Discurso en loor de la poesía», una de las escasas poéticas que adornan los siglos coloniales y una de las piezas que mayor interés crítico han despertado, aunque 
sólo fuera por la tentación de desvelar la identidad de su anónima autora. Pocos han reparado en el corpus central del Parnaso Antártico, la traducción de las Heroidas ovidianas, sobre la que merece la pena hacer algunas puntualizaciones.

\section{El libro, Ovidio y las Heroidas}

La obra de Mexía aparece con todos los elementos que caracterizan los preliminares de una obra de su época: prólogo, dedicatoria, poemas de elogio, aprobaciones y licencia. El prólogo está incrustado entre sonetos y otras composiciones de alabanza al poeta y su fruto, de acuerdo con la línea laudatoria típica. Consta, en este orden, de: la aprobación, una dedicatoria, un soneto del licenciado Pedro de Oña - en nombre de la Antártica Academia de la ciudad de Lima-, un soneto del Dr. Pedro de Soto - en nombre del claustro de la Universidad de México-, el soneto de Luis Pérez Ángel «El autor a sus amigos» - prólogo del libro-, una vida de Ovidio, el "Discurso en loor de la poesía», un soneto de Mexía dedicado a la autora del «discurso», la traducción de las veintiuna epístolas ovidianas y la «Invectiva contra Ibis», más dos sonetos finales, uno del capitán Cristóbal Pérez Rincón y otro de Mexía, como respuesta.

Sabemos que Mexía «se despachó a la provincia de Tierra Firma, por mercader» el 6 de marzo de 1582, según consta en la documentación del Archivo de Indias ${ }^{3}$. Allí, en América, redactaría su obra titulada Primera Parte del Parnaso Antártico 4 y la publicaría en Sevilla en 1608.

La ajetreada vida que llevó (de Tierra Firme a Perú, de allí a México, su vuelta de nuevo a Perú, sus viajes a España) choca de entrada con su actividad literaria. Resulta sorprendente que una labor como la suya, que implicaría, desde nuestra perspectiva, tranquilidad y reposo, haya sido realizada en las condiciones de agitación que en el prólogo del Parnaso Antártico se refieren. Por sus palabras sabremos que en 1596 viajó de Perú a Nueva España, «más por curiosidad de verlos que por el interés que por mis empleos pretendía». En la mejor línea de las relaciones de Indias, marcadas por el desastre, se mueve su relato del viaje. Penalidades marítimas, incluyendo naufragio, tormentas y muerte de un compañero («mi navío padeció tan grave tormenta en el golfo llamado comúnmente de Papagayo, que a mí y a mis compañeros nos fue representada la verdadera hora de la muerte»), calamidades que se ven prolongadas con las ocurridas en el camino por tierra: aguas, lodos, pantanos, ríos peligrosos, pueblos mal pro-

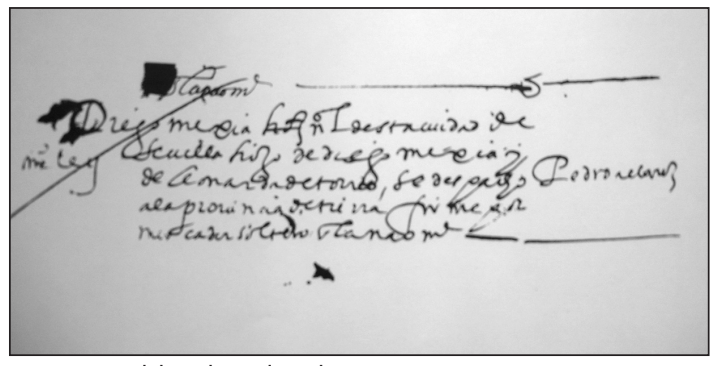
Documento del Archivo de Indias. veídos, peste, y todo un largo etcétera, que hacen cada vez más difícil la situación, adobada por el cansancio físico del medio de transporte, pues va en mula desde Acaxú (Acajutla) a México capital.

Para entretener su tiempo, según confiesa, compró una edición latina de las Heroidas a un estudiante en Sonsonate e inició la traducción de la misma durante el viaje y, según relata, halló «traducidas en tres meses de veintiuna epístolas, las catorce», completando el resto durante su estancia en la capital, que se prolongó más de un año. Era Mexía buen conocedor de los clásicos, a los que leía con regularidad, pues además de su admiración por toda la obra y vida de Ovidio, otros autores como Virgilio u Horacio son citados en el prólogo de su obra.

Latinistas pasados y actuales han calificado de «muy importante y muy hermosa» la traducción de Mexía. Prueba de su importancia son las repetidas ediciones españolas de las Heroidas que han seguido manteniendo la versión de Mexía. Elogiada por Menéndez Pelayo y Quintana, fue elegida por la «Biblioteca clásica», Madrid, 1914. Continuas reimpresiones nos llevan, por ejemplo, hasta 1946, a la edición realizada por la editorial Aguilar, colección Crisol (Madrid).

Entre el tópico y la sinceridad se mueven sus palabras preliminares, se queja del «rústico estilo» de su traducción, de su condición de imitador más que de traductor e insiste en la finalidad de entretener antes que en la presunción de ingenio, pero al mismo tiempo, con plena conciencia de su trabajo, justifica la elección del terceto por parecerle que se corresponden esas rimas con el verso elegíaco latino, al tiempo que reconoce adornarlas con «argumentos en prosa y moralidades» siguiendo el principio del prodere et delectare. Como hombre culto no escatima la alusión a las fuentes y a los comentaristas del sulmonés, marcando su filiación renacentista italiana en la consideración a Hubertino, Asensio, Juan
3 AGl, Contratación, 5538, I, 367 v. 4 Una edición facsímil de la obra se debe a Trinidad Barrera, Primera parte del Parnaso Antártico, Roma, Bulzoni, 1990. Por ella citaremos.

De Academias, transterrados y parnasos antárticos TRINIDAD BARRERA LÓPEZ 


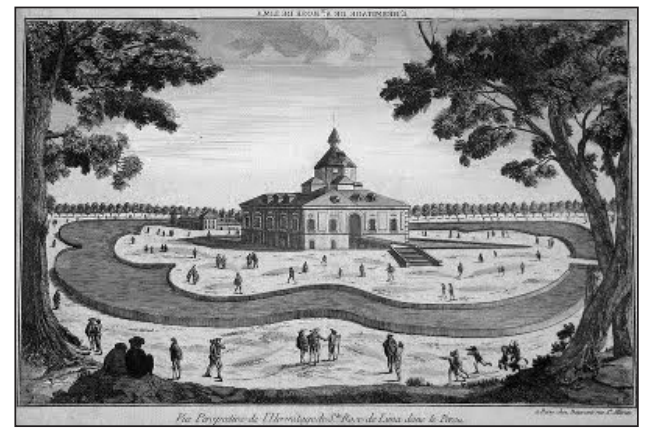

Ermita de Santa Rosa de Lima.

5 Ibid., p. 9.

6 Ibid., p. 11.

7 Ibid., p. 11.

8 Ibid., p. 11.

9

Rudolph Shevill, Ovid and the Renaissance in Spain, Berkeley, 1913.

De Academias, transterrados y parnasos antárticos

TRINIDAD BARRERA LÓPEZ una poética.
B. Egnacio, el veneciano, y Remigio Florentino, buscando también un espacio entre los seguidores ovidianos que el tiempo sin lugar a dudas le ha dado, y aún dice: «Además añadí conceptos y sentencias mías, así para más declaración de las de Ovidio, como para rematar con dulzura algunos tercetos» ${ }^{5}$.

Son curiosos los comentarios que hace en el prólogo sobre el ambiente intelectual mexicano de fines de siglo que pinta más preocupado por hacer dinero que por tratar del verdadero metrificar hasta el punto de que «el que más docto viene se vuelve más perulero» ${ }^{6}$. El siglo XVI que describe aparece marcado por el interés y ganancia: «Pues para leer y meditar ¿cómo habrá tiempo si para descansar no se alcanza?»7. La comparación con España no se hace esperar y con ello su añoranza de una vida más acorde con las inquietudes del espíritu, situación que aprovecha para elogiarse: «mil veces dignos de ser alabados los que a cualquier género de virtud se aplican en las Indias, pues demás de no haber premio para ella, rompen con tantos montes de dificultades para conseguirla» 8 y llega a comparar su situación con la de Ovidio en el Ponto.

La Primera Parte del Parnaso Antártico es indudablemente un libro que Mexía ideó como homenaje a Ovidio. Su cuerpo principal es la traducción de las Heroidas y el In Ibis, desgarrada autodefensa de la injusta situación de expatriado y le antecede una breve biografía de Ovidio. La admiración por el poeta latino es abierta desde el principio. La elección de las epístolas ovidianas marca su orientación renacentista, y además en el interior del libro el «Discurso en loor de la poesía» lo firma una poetisa anónima peruana, heroica dama como las heroínas ovidianas, enamorada del sevillano, y que suministra una amplia información de la Academia Antártica así como de sus componentes. Si Ovidio con sus epístolas ha podido ser considerado por algunos críticos como un pionero defensor de los derechos de la mujer, el «discurso» de esta dama peruana resulta un pórtico adecuado como defensa del propio Mexía de los derechos que tiene la mujer al saber y su manifestación, pues no deja de ser una rareza poner en pluma femenina
En las páginas que dedica a la «Vida de Ovidio» llega a decir: «Reverenció a los poetas sus antecesores, y trató benévolamente con sus compañeros. Fue tan suave y apacible en cuanto escribió (que según veremos en su Invectiva) jamás hizo sátira, ni ofendió a persona con sus versos: virtud tan admirable y tan digna de imitación de los cristianos poetas. Fue de virtuosas costumbres, bebía poco vino, y muy aguado, y con sumo estudio y pureza de ánimo huyó el pecado abominable, por cuya razón leo sus obras con aficionados ojos». Manifestaciones de esta naturaleza, que muchos estudiosos de Ovidio no compartirían, explican quizás la vena religiosa que se desprende de la lectura de su Segunda Parte del Parnaso Antártico. Queda pues por hacer un cotejo entre ambos libros y quizás se descubran paralelismos interesantes, la utilización en ambos del terceto encadenado, por ejemplo, como ocurre en la «Epístola a D. Diego de Portugal», perteneciente a esta Segunda Parte.

Parece oportuno preguntarse por qué el elogio a Ovidio y sus Epístolas heroicas. La importancia de Ovidio a lo largo del tiempo es un hecho aceptado. Su influencia fue notable en gran número de escritores, entre los clásicos, Lucano, Estacio, Marcial, Manilio, Séneca, Petronio, etc. La Edad Media fue calificada por Traube como aetas ovidiana, y para el Renacimiento (incluyendo al Renacimiento español) las Epistolas de Ovidio constituyeron piezas clave. Ovidio y las Heroidas gozan de exhaustivos trabajos. Para ver la presencia de Ovidio en España, sobresale el bien documentado y ya clásico análisis de Rudolph Shevill ${ }^{9}$ que rastrea concienzudamente su pervivencia desde la literatura medieval hasta el siglo XVI.

El éxito de Ovidio se ha enfocado desde diversos ángulos: como poeta galante, como poeta del amor, el de las leyendas de las $\mathrm{Me}$ tamorfosis, el del mito, el poeta del sufrir en el exilio, o el de la desgracia inmerecida. Cada uno se ha acercado al sulmonés por uno $u$ otro motivo, perpetuando su presencia: italianos, franceses, ingleses, o españoles. Entre estos últimos, Juan de Mena, el Arcipreste de Hita, Fernando de Rojas, Cervantes, Lope de Vega, Quevedo. De la imitación directa a los ecos lejanos, todos enaltecen el modelo imitado o admirado.

La identificación del poeta sevillano con Ovidio la señala él mismo: en dos ocasiones 
compara la propia situación con la suya: «Pues muchas veces me acontece lo que a Ovidio estando desterrado entre los rústicos del Ponto [...] que queriendo hablar romano habla sarmático [...] El que más docto viene se vuelve más perulero, como Ovidio a este propósito lo afirma de los que iban a los getas, en el cuarto del Ponto, escribiendo a Severo» ${ }^{10}$.

Resulta sorprendente este paralelismo que establece entre su vida en América y la de Ovidio en el Ponto. Y es que aunque las razones que llevaron a uno y a otro a habitar en tierras tan lejanas de su lugar de origen no son las mismas, sí lo son los resultados. El sevillano tenía conciencia de desterrado en las áridas márgenes de la civilización y deseaba su reincorporación al centro originario de cultura, España. La prueba es que su libro lo manda a España para publicarlo, aún a sabiendas de la temeridad que implicaba (pérdida o robo, por ejemplo).

Además de lo dicho, Diego Mexía se nos antoja en la postura del escritor manierista que se declara discípulo continuador de alguien, en su caso de Ovidio. El principio de imitación lo recoge en su prólogo: «Aunque he usurpado algunas licencias, de suerte que puedo ser mejor llamado imitador que traductor». En 1541 se publica el tratado de Bartolomeo Ricci, De imitatione (Venecia), donde parece indicarse que dentro del género imitatio se hallan tres categorías: sequi, imitare, aemulare. La gran mayoría de las traducciones del Renacimiento son, en realidad, imitaciones más o menos cercanas al modelo, tal como ocurre en el caso de Mexía. La imitación de éste estaría, a veces, más próxima a la paráfrasis de que habla Dryden, cuyo intento es traducir el sentido más que cada una de las palabras. La traducción justa sería la metáfrasis, es decir, seguir palabra por palabra y línea por línea, algo que sólo en escasas ocasiones hace Mexía. Es importante tener en cuenta que la práctica común de las escuelas humanísticas era entrenar a los alumnos en la translatio, paraphrasis, imitatio, intentando delimitar las fronteras del recorrido que va desde la traducción hasta el poema original.

Es evidente que Mexía imita a su manera. Es decir, se ajusta al modelo en su conjunto e introduce variaciones parciales. Ocurre que el sevillano «imita» a aquel que, salvando las distancias, se sitúa en la Antigüedad en una posición comparable a la propia y así, al re- ferir la vida de Ovidio, nos dice: «Resplandeció Ovidio su retórica y poesía sobre todos los de su edad, pero juzgando el padre ser este estudio de tan poco fruto y utilidad (como lo es en nuestros tiempos)»11. El pasado se espeja en el presente. Mexía se nos aparece así como perteneciente a una larga galería de retratos en la que Ovidio se perpe-

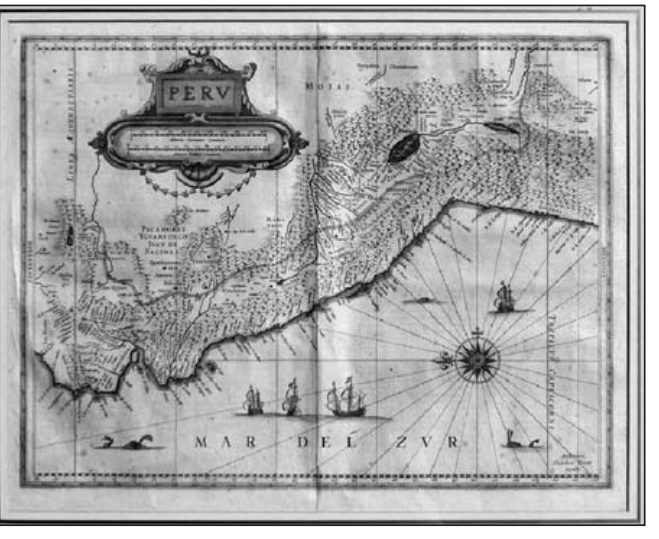
túa. La identificación con el modelo es un punto de partida, la traducción de las Heroidas tiene allí su razón de ser; pero además dicha versión se le presenta como la vía más razonable de reintegración a la metrópoli, sinónimo de esplendor cultural, donde la huella de Ovidio no había perdido ni un ápice de importancia.

Las Heroidas se componen de veintiuna cartas de amor, escritas casi todas por mujeres que son heroínas de la mitología, excepto Safo. Sólo toman la pluma tres hombres: $\mathrm{Pa}-$ ris, Leandro y Aconcio. A ellos les responden sus amadas. Una salvedad, la carta veinte, en la ordenación de Mexía, "Cidipe a Aconcio», está en su versión abreviada. En realidad aparece así en casi todos los manuscritos latinos de las Heroidas. Estas piezas contituyen un punto clave del Renacimiento epistolar. Como ha señalado Antonio Prieto «las Heroidas van a conjugar, en el tiempo joven de Ovidio, los tiempos cumplidos de la etopeya y el por cumplir de la suasoria. Van a perturbar el orden de esos tiempos con la creación de un tiempo acrónico, y la juventud de la Edad Media va a recoger esa creación contra la ordenación práctica y mediata del Ars dictan$d i{ }^{12}$. Desde el punto de vista de la reforma, las Epistulae Heroidum pertenecen a una retórica epistolar con determinada función comunicativa, donde la finalidad didáctica se ve sobrepasada por la dimensión artística. El renacentista apreciará en las epístolas ovidianas dos aspectos, la consolatio, consuelo de la carta al que escribe, y el encanto de la palabra $\mathrm{u}$ olvido del receptor por parte del que escribe. En definitiva, lo que vence es el arte de la palabra en sí misma para, a través de ella, narrar un sentimiento.

El valor de las Heroidas y su gran aceptación como modelo no debieron ser ajenos al sevillano, ya que dentro de este libro se
10 Ibid., p. 11.

11 Ibid., p. 13.

12

José María Prieto, La prosa española del siglo XVI, Madrid, Cátedra, 1986, p. 61.

De Academias, transterrados y parnasos antárticos TRINIDAD BARRERA LÓPEZ 
Recientemente se ha publicado una edición del "Discurso en loor de la poesía» al cuidado de Raquel Chang-Rodríguez: Clarinda y Amarilis, Discurso en loor de la poesía. Epístola a Belardo, Lima, Pontificia Universidad Católica, 2009.

14

Primera Parte, p. 15.

15

El título metafórico de Bursario sugiere que las enseñanzas del libro merecen guardarse en la bolsa de la memoria.

16

Pilar Saquero y Tomás González Rolan, El bursario, Madrid, Universidad Complutense, 1984, p. 31.

De Academias, transterrados y parnasos antárticos

TRINIDAD BARRERA LÓPEZ incluye otra pieza, escrita por una «señora principal de este reino» y dedicada a Mexía, donde ésta expone sus opiniones poéticas y su predilección cultural, utilizando, como en la traducción ovidiana, los tercetos encadenados. La elección del mismo molde poético pudiera apuntar a que «Discurso en loor de la poesía» ${ }^{13}$ ejerce una función proemial con respecto a la traducción. El paralelismo entre el «Discurso» y las Heroidas lo realiza el autor cuando dice: «Con el cual discurso (por ser una heroica dama) fue justo dar principio a nuestras epístolas» ${ }^{14}$. Apócrifa epístola heroica la de Clarinda, que comparte con las ovidianas, además de molde estrófico, los dramatis personae, mujer-hombre, destinador y destinatario del mensaje, unidos por una relación que oscila entre la amistad y la admiración, aunque está claro que las cuitas allí tratadas no son de orden amoroso, sino del don de la poesía:

\section{Si, oh gran Mexía, en tu esplendor me inflamo \\ Si tú eres mi Parnaso, tú mi Apolo \\ ¿Para qué a Apolo y al Parnaso aclamo? \\ Tú en el Perú, tú en el Austrino Polo \\ eres el Delio, el Sol, el Febo santo. \\ Sé pues mi Febo, Sol y Delio solo.}

Febada tuya soy; oye mi canto. [vv. 40-45 y 48]

Las epístolas ovidianas se ajustan a la preceptiva al uso: un saludo inicial con los nombres del remitente y del destinatario, $y$ la despedida. En el «Discurso» no aparece, como es sabido, el nombre de la heroica dama, aunque sí su condición femenina: «En hombros de mujer que son de araña», ajustándose a la normativa en lo referente al destinatario y a la despedida. El parentesco entre una y otra viene dado por la condición femenina de quien escribe y éste es un detalle que nos remite de nuevo a Ovidio, quien, en su Ars Amandi (m, 346), aconseja a las mujeres la lectura de los poetas.

España contribuyó desde la Edad Media a la traducción de las epístolas ovidianas, ya fuera dentro de compilaciones, ya en versiones independientes. El primer caso en la lista de traductores lo ofrece Alfonso X el Sabio, que las tradujo, aunque no en su totalidad, para introducirlas en la General estoria y en la Crónica general. Once son las epístolas que insertó, las II, IV, V, VI, X, XI, XII y XIV en la segunda parte de la General estoria; la I y la
VIII en la tercera parte y, finalmente, la VII en la Crónica general. Para Alfonso X, Ovidio se ajusta al principio prodere et delectare, y eso es esencial en su época, donde lo didáctico y lo moralizante ocupaban un primerísimo lugar. También Mexía hace honor a dicho principio en su prólogo: «La poesía que no deleita sin aprovechar con su doctrina no consigue su fin». Otro punto de coincidencia es el capítulo de supresiones o adiciones a la traducción por pruritos cristianos: «He quitado todo lo que en algún modo podía ofender a las piadosas y castas orejas, dejando de traducir algunos dísticos no tan honestos como es razón que anden en lengua vulgar», dice Mexía.

El éxito de la traducción alfonsí sirvió a las Sumas de historia troyana, atribuidas a un supuesto Leomarte, donde se intercalan resumidas las epístolas V, VI, VII, IX y XII.

El siguiente ejemplo es la obra de Juan Rodríguez del Padrón, conocida con el nombre de Bursario, quien acomete la empresa de traducirlas en su totalidad, excepto la $\mathrm{XV}^{15}$. Dicha versión ofrece, como en el caso de Alfonso $\mathrm{X}$, epígrafes introductorios a cada epístola, que O. T. Impey suponía inspirados en el monarca, mientras que Saquero y González Rolan demuestran que las diferencias son tantas que la solución radicaría en el hecho de que Padrón utilizó «además de un códice latino de las Heroidas de Ovidio [...] un comentario latino a esta obra, con el que confeccionó la introducción de todas las cartas» ${ }^{16}$. Y citan el libro Publii Ovidii Nasonis Heroides cum interpretibus Hubertino Crescentio et I. Parrhasio, Vennetiis, 1543.

Ya apuntamos cómo la traducción de Diego Mexía contenía asimismo dichos comentarios, dándose la coincidencia de que el libro citado es el primero de los que nuestro autor enumera en su prólogo como matriz de su edición. Luego debemos suponer que los epígrafes de Mexía remiten también a los manuscritos con glosas o accensus citados en dicho prólogo.

Tras Alfonso X y Rodríguez del Padrón circularon varias traducciones parciales en prosa y verso con comentarios añadidos a algunas de ellas (Moya, 1986: 49-54; Alatorre, 1950: 162-166). Merecen destacarse las de Gutierre de Cetina, anteriores a 1560: las cartas I y II, las de Penélope y Fillis. También se le atribuye una de Dido a Eneas, aunque no hay unanimidad crítica con la traducción de las epístolas ovidianas en verso suelto, rea- 
lizada por Francisco de Aldana, el Divino, y otra de Ramírez Pagan, perdidas.

Respecto a los matices americanistas que Mexía deslizó en sus traducciones nos da cuenta Gil ${ }^{17}$, a propósito de ciertas libertades que se toma el sevillano frente al texto de Ovidio, matizando la situación con alusiones frecuentes a los peligros del mar, por ejemplo en la carta de Dido a Eneas, habla de un «cosario estraño» o de los continuas peripecias marítimas, naufragios y tormentas, no sólo en la carta de Penélope a Ulises sino en otras epístolas, que son cosecha de Mexía, como lo es la alusión a Paris por parte de Helena que habla del «Polo nuestro». Aunque quizás el caso más curioso sea la alusión a los terremotos en el In Ibis, inexistente en el texto ovidiano pero que denuncia probablemente que en la mente del sevillano estuvieran los desastres limeños de 1586 y 1609. Menos convincente me parece la lectura de Gil a propósito de la palabra «cerro» en el terceto de la epístola a Dido, cuando lee: «Traslada a Troya mas felicemente/ en mi Cartago i en la Tiria tierra,/ I ten su cerro como Rei potente», inclinándome más bien por la lectura de «cetro», más coherente con el contexto ${ }^{18}$.

Aunque Diego Mexía era español, conviene plantearse la influencia que Ovidio tuvo en México durante los primeros siglos virreinales, pues no hay que olvidar que fue allí donde el sevillano gestó sus traducciones. Según apunta José Quiñones ${ }^{19}$, este magisterio se da de tres formas: desde obras de Ovidio impresas en México, a través de los traductores de Ovidio en México y mediante la influencia de Ovidio en escritores mexicanos. Si, como sabemos, la importancia de Ovidio en la literatura española es notable, otro tanto ocurrirá en el Virreinato de Nueva España. Serán las Metamorfosis el libro más influyente, mientras que los primeros textos impresos corresponden a algunas elegías de las Tristia y Epistulae ex Ponto, y su primera traducción de las Heroidas. Hay que esperar la llegada de los jesuitas, en 1572, para poder hablar de un estudio sistemático de los clásicos, lo cual no quiere decir que no se desarrollasen intentos parciales con anterioridad, gracias a la labor de otras órdenes religiosas de cuya actuación nos quedan pocos testimonios. A la Compañía de Jesús se debe la lista de libros presentada a la aprobación del virrey Martín Enríquez, con vistas a su impresión y destinada a los estudiantes de sus colegios. Entre los veinte libros que contiene la lista, con fecha 16 de febrero de 1577, se encuentra la obra de Ovidio, De Tristibus et ex Ponto.

Hasta 1636 no encontramos una obra de Ovidio editada en la capital que contenga parte de las Epistolas heroicas (I y VI. Me refiero al Florilegium donde, junto a la selección de las Heroidas, Tristia y Ex Ponto, hay poemas de Horacio, Marcial y otros). A este volumen le habían precedido dos, aunque ninguno de ellos recogía las Heroidas. Son éstos el ya citado de 1577 y el Poeticarum institutinum liber, 1605, especie de antologías de la estética de los géneros poéticos que incluyen, junto a Ovidio, a Virgilio, Claudiano, Silio Itálico, Séneca, Terencio, Horacio, Tibulo, Propercio y Marcial. De Ovidio ofrece una selección de Metamorfosis, Amores, Tristia y Ex Ponto.

Llegamos así a Diego Mexía, autor de la primera versión al español de las Heroidas en su totalidad, realizada en México, aunque publicada en España; libro valioso, feliz combinación de creación, imitación y traducción que evidencia el tino poético de su autor, el transterrado humanista que, tras cruzar mares y tierras, "por diferentes climas, alturas y temperamentos», consiguió la fama de poeta al tiempo que hacía oír otras voces trasatlánticas, eco de un nuevo Parnaso, el Antártico, que, no por alejado de su cuna, merecía ser desoído. Pero esa sería otra historia.

Para finalizar quisiera insistir en que aunque el interés de los estudiosos de la Colonia por el «Discurso» empezó a cobrar nuevo impulso en la década de los noventa, no ocurrió así con la totalidad del libro. Todavía hoy, al enfilar el siglo XXI, no sólo sigue inédita en la Biblioteca Nacional de París la Segunda Parte del Parnaso Antártico, sino que no disponemos de una edición crítica, anotada convenientemente, de la Primera Parte del Parnaso Antártico y creo que es una tarea necesaria en la recuperación de los textos de la colonia.
17

Ob. cit., pp. 122-126.

18

En la edición que manejo se lee claramente "cetro».

19

José Quiñones, «Influencia de Ovidio en México: siglos XVI-

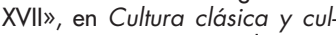
tura mexicana, coordinación de José Tapia Zuñiga, México, UNAM, 1983, pp. 151-170.
De Academias, transterrados y parnasos antárticos

TRINIDAD BARRERA LÓPEZ 